\title{
UKRN Position on Responsible Research Evaluation
}

The UK Reproducibility Network Steering Group

$4^{\text {th }}$ May 2021

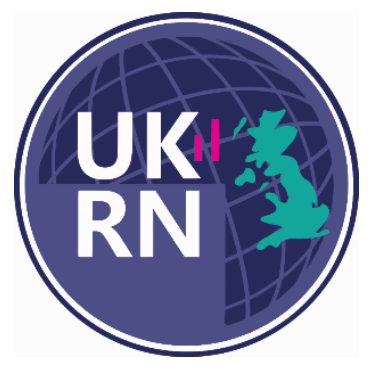

We appreciate that universities are not immune to financial pressures, and that there may be times when they have to reduce their headcount or re-align their priorities. However, the resulting career uncertainty has the potential to encourage researchers at all stages to prioritise research goals that are likely to have short term impact, and (in particular) strategies that may contribute to lower quality research findings.

We are therefore concerned when certain criteria are used - grants received and papers produced - when these are exactly those thought to contribute most to a hyper-competitive research environment, and ultimately to have a negative impact on the quality of research outputs. We have produced a Common Statement on Responsible Research Evaluation, published under a CC BY license, available for institutions to adopt and adapt as necessary.

We encourage institutions to be transparent about any metrics used and their method of calculation, including whether other factors are taken into account (e.g., appraisals over multiple years, seniority) and whether a clear and auditable procedure is in place that can account for individual circumstances (e.g., workload, illness, career breaks). Otherwise, the use of metrics risks being discriminatory, and ultimately detrimental to the quality of research produced.

\section{(c) (1) ()}

This work is licensed under a Creative Commons Attribution-ShareAlike 4.0 International License. 